\title{
Per Enflo's personal thoughts about Victor Lomonosov
}

Early in 1973, there was excitement in the mathematical world. A young mathematician from Russia, Victor Lomonosov, had proved that operators commuting with a compact operator on a Banach space have invariant subspaces. The short, elegant proof had made 40 years of development obsolete. I was at UC Berkeley at that time. I remember that the leading operator theorists there immediately started to work hard to see if the new powerful technique could solve the entire invariant subspace problem. It seemed hopeful that this was within reach, since Lomonosov's proof even showed, that an operator commuting with an operator which commutes with a compact operator has invariant subspaces. They did not succeed, but even so it was clear that Lomonosov's new ideas had already forever changed the field of operator theory.

Who was Victor Lomonosov? It seemed that nobody at Berkeley had met him or knew anybody who had met him. Could it even be that "Lomonosov" was a made up name for the collaboration of several mathematicians, like the French "Bourbaki" ?

Fifteen years later, in the early summer of 1988, when I was sitting in my office at Kent State University, my telephone rang. The person introduced himself as Victor Lomonosov. He was visiting a friend in the US. The friend quickly took over the telephone conversation and I learned that Victor Lomonosov had plans to return and emigrate to the US in early 1989. To me, this phone call was extremely surprising, almost spooky, and at the same time very exciting. So I asked Victor to contact me immediately when he was back in the US.

When Victor came back in early 1989, I tried all regular ways to find some short term employment for him at Kent State University. But there was no money anywhere. I knew that President Michael Schwartz had the ambition to make Kent State a top level research university and I knew that he had faith in me. So I went to a reception which he was going to attend. I took him aside and I told him that Kent State had an opportunity to hire a mathematician who had just come out of the Soviet Union, and who had done some sensational, groundbreaking work. Although this work was 15 years in the past, chances were that he was still a top level mathematician. Michael Schwartz remarked that there might be political reasons for the long silence and then he asked me three questions: "Does he speak English?” I answered: "He seems very ambitious to learn to speak better.” Next question: “Is he as good as you are?” Before I had commented, he continued with the third question: "Do you want him here?" So I said: "YES!" Then he said: "We will get him!" And two days later, there was money to hire Victor for 6 months. And long before the end of these 6 months, it was clear that Kent State had made a great decision. Victor got offers from several other universities, but he stayed at Kent State. And over the years he made a very important contribution 
to the mathematical life of Kent State University, mainly through his own work but also through his many contacts with mathematicians from the former Soviet Union.

Not surprisingly, the cultural differences between the Soviet Union and the US sometimes showed up in the beginning of Victor's stay. Here is one example:

An American to Victor: "Oh, you do not have social security numbers in the Soviet Union. But how do you then count people?"

Victor: "One, two, three..."

I met almost daily with Victor in the beginning of his stay. We usually had lunch at Burger King, and we discussed daily life issues and mathematics. Victor worked hard to adjust to American life. Getting a driving license as quickly as possible was important. He brought his English-Russian dictionary to the written test and was allowed to use it "as long as it does not have any Ohio traffic laws in it."

And he worked hard to improve his English, by talking, reading and watching TV. In the years around 1990, perhaps in connection with the financial crisis, it had become common to blame students' failures on their professors' poor English. So, for Victor getting a tenured position at Kent State, it was clear that this could be a potential issue. But, with Victor's fast learning, nothing happened like that.

At the same time, as Victor adjusted to a life in the US, he developed his deep, ingenious, and beautiful theory of operator algebras on Banach spaces. It is based on an inequality which, when specialized to finite dimensions, gives Burnside's classical theorem. And, besides strengthening and improving many earlier results on operator algebras and invariant subspaces, it suggests the following, in some sense ultimate, conjecture for a "positive" answer to the invariant subspace problem: If $A$ is an operator on a Banach space, then $A^{*}$ has an invariant subspace. In later work, he developed further his work on extensions of Burnside's theorem.

Victor's remarkable ability to find new approaches to difficult problems led to another great triumph, when he solved the long-standing problem of whether the Bishop-Phelps' theorem holds for Banach spaces over the complex field. One version of the celebrated Bishop-Phelps' theorem from the early 1960s states that, in a Banach space over the real numbers, a closed, bounded, convex set has a support point, that is, a point where some functional attains its supremum.

In 1977, J. Bourgain proved that for Banach spaces with the Radon-Nikodym property, this holds also for Banach spaces over the complex field.

In 2000, Victor gave an example of a closed, bounded, convex set without support points in a Banach space over the complex field. And in a subsequent paper he showed that the complex version of Bishop-Phelps' theorem fails in every space which is a predual of any uniform nonself-adjoint dual operator algebra. So, his counterexample is not just an isolated "pathology," but rather it is part of a more general phenomenon.

As I already mentioned, Victor had a remarkable ability to find new approaches to difficult problems. In his own work, he was looking for new, powerful ideas. And his own papers are usually not very long. The paper "Exponential numbers of linear operators in normed spaces” started as a 4-page paper by Victor and myself. We thought 
that the paper had a nice idea, worth publishing. V. Gurariy joined us, and the paper grew to a 15-page paper. Then Yu. I. Lyubich joined us and it was eventually published as a 35-page paper.

Victor frequently collaborated with other mathematicians. In his joint publications-papers of high quality - there is a broad span of topics, from analysis to almost pure algebra. My discussions with him fell mostly within the area of operator theory. And for me, they were an important inspiration, both for my own efforts and for my work with doctoral students. Our discussions continued to the end of his life. I remember that, shortly before his passing, we considered the following question to which none of us had an answer: Consider a one-to-one operator $T$ with dense range. For which $T$ is there an operator $V$, similar to $T$, such that $V$ and $V^{*}$ have the same range? Such that $V$ and $V^{*}$ have disjoint ranges, except for $\{0\}$ ?

Victor's work has had a great impact. Several of his results are now classical and parts of standard courses in functional analysis. They are famous, not just among functional analysts, but in the entire mathematical world. 


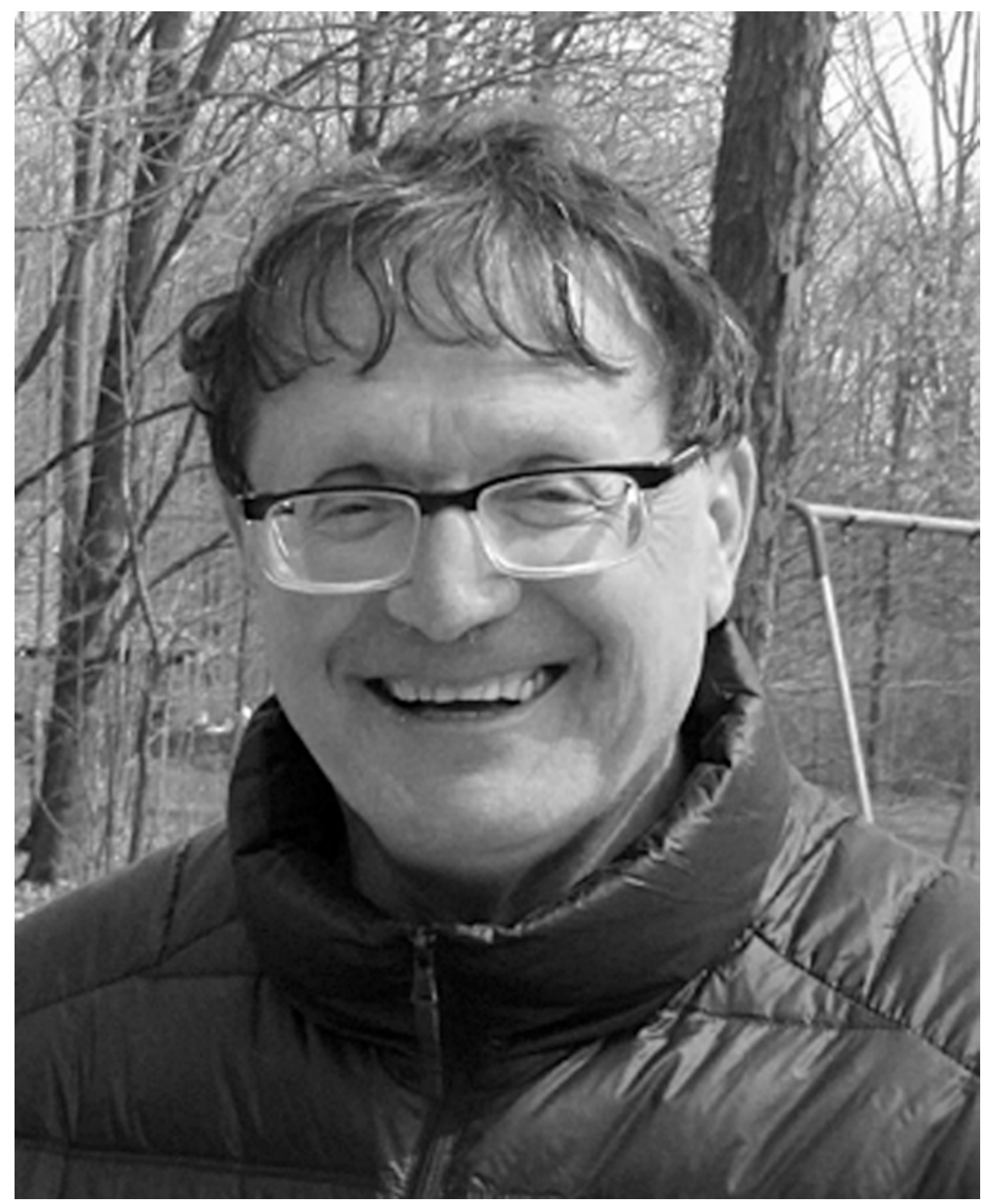

Photo of Victor Lomonosov 